\title{
Refugees Adaptability on the Peaceful Coexistence with the Host Communities. A Case of Rwamwanja Refugee Camp- Uganda
}

\author{
Doreen Basemera $^{1}$, David Lwanga ${ }^{2}$ \\ ${ }^{1}$ Mountains of the Moon University \\ Uganda \\ Email: amootido [AT] gmail.com \\ ${ }^{2}$ Mountains of the Moon University \\ Uganda \\ Email: vividlwanga $[\mathrm{AT}]$ gmail.com
}

\begin{abstract}
This article looks at the possible ways for refugees to have peaceful coexistence of refugees with their hosts based on an understanding of the causes of conflict between refugees and host communities and how the existence of refugees impacts the lives of the host communities which also has a bearing on peaceful coexistence. Based on the descriptive design that employed both qualitative and quantitative approaches, the results are that there is a relationship between causes of conflicts and the peaceful coexistence of refugees in the Rwamwanja refugee settlement. The article also indicates that political incitement was the main cause of conflict, that illiberal and illiterate people within and outside the camp provided leeway for violence, and this affected peace negatively. The article further indicated that poverty, inequality, and marginalization or lack of respect were the major reasons for violence in the Rwamwanja refugee settlement. The article recommends that the government and the settlement management should initiate sustainable livelihoods through small-scale businesses among the people in the settlement to shock-absorb idleness and unemployed refugees and host community members who are blamed for violent inter-ethnic conflict. The article further recommends that Nongovernmental organizations and other religious societies, self-help groups, and Districts efforts should be strengthened by the government of Uganda and other stakeholders to aid in poverty reduction initiatives and promotion of peaceful coexistence among the refugees and host communities for socio-economic development in the area. Further at the policy level peaceful coexistence between refugee and host communities is possible if approaches like the degree that locals recognized their benefits from projects and services provided to refugees, clear guidelines for implementing local integration, including readily available information for refugees, guide how to distribute resources or implement programs, host governments should be clear towards local integration, meet their responsibilities to improve socio-economic conditions in areas affected by protracted refugee situations and support the full integration of refugees instead of confining them to camps.
\end{abstract}

Keywords---- Refugees, Peaceful Coexistence, Host Communities, and Adaptability

\section{INTRODUCTION}

According to the UNHCR (2012) Global Trends Report, the number of refugees worldwide stood at 45.2 million people of these third world countries host over eighty percent $(80 \%)$ of the total world refugee population an increment of ten percent $(10 \%)$ compared to a decade ago. These refugees are accommodated in various refugee camps across the world where provisional settlements have been established to host people running away from their home countries as they tried to seek safety. Any time there was a need for the establishment of a refugee camp it was usually done in places that were away from towns or cities, from borders and war-torn zones. These are not unoccupied areas as they had local communities who were already settled and going about their day-to-day activities. Owing to this fact, establishing a refugee camp and the settling of refugees in these communities had a significant impact on the lives and livelihoods of persons living in that area. The presence of refugees can create tensions and conflicts with host communities for many reasons. First, refugees are often well served by humanitarian agencies and enjoy better access to water, food, health, and education than the host population (OECD 2001, Ikanda 2008, Charny 2009). As well as being poorly served by humanitarian agencies, host communities tend to exist in regions that are often neglected by the state (Dryden-Petersen \&Hovil 2003, Ikanda 2008, and Agblorti 2011). Due to the physical separation that often exists between refugees and host communities, the benefits enjoyed by refugees may be exaggerated in the eyes of host communities, driving further tension between the two groups (Dryden-Petersen \&Hovel 2003). Chamber (1986) articulated that the consequent effect of refugees' settlement to the host 
community forced them to formulate strategies to accommodate the new developments and challenges in their society. Despite the various strategies to address the crisis of refugees and host communities they continued facing deplorable situations (UNHCR, 2011). The effects of hosting refugees to the host community are both negative and positive, thus creating a situation of both winners and losers. The struggle has escalated the abuse of human rights and other consequences of a violent community. Given the status of economic development of most developing countries characterized by unequal distribution of resources, unemployment, underserved by government programs create a struggle for access to the limited resources. Allocating refugee camps in such communities battling with inadequate resources resulted in conflicts and abuse of human rights. The influence of refugees on the lifestyle of the host community was often coupled with challenges especially in the initial influx phase as well as in long-term presence characterized with continued conflicts resulting in competing for resources and social services. This calls for a need to find ways of how refugees can coexist with the host communities. Whereas the existing literature has shown the challenges facing local integration of refugees and efforts the different governments have put in place, in recent years no single work has been put together to show how the peaceful existence between refugees and host communities depends on the refugee's adaptability. To understand the dynamic of the conflict between refugees and their host communities and how possible these can coexist a study was conducted in Rwamwanja refugee settlement which is located in Kamwenge District, South Western Uganda. Rwamwanja sub-County is a cosmopolitan society and its local citizens still hold to their ethnic consciousness which triggers inter-group conflicts, normally based on consensus. Many scholars have described these conflict resolution processes as peace-building (Assefa, 1993; Lederach, 1995; Baresh and Webel, 2002). Kalemera (2017) stated that the district has got 5 sub-counties, of Nkoma which applied for a Town council (Katalyebwa), Bisozi, Mabaale, Kiduduma, and Kaberebere sub-county.

\section{BACKGROUND OF THE STUDY}

The UNHCR (2012) Global Trends Report, reported the number of refugees worldwide stood at 45.2 million people, of this population, $46 \%$ were children below the majority age while women and girls accounted for $48 \%$. In the same year, war and persecution forced an average of 23,000 persons per day to leave their home countries in search of protection elsewhere, either within the borders or in other countries. The report further indicates that Pakistan led in hosting the largest number of refugees, 1.6million in the year 2012 while Afghanistan, remained the principal source of refugees across the globe, a position it held for the last three decades. UNHCR, (2017) reported that around 3\% of the world's population $(n=214$ million people) has crossed international borders for various reasons. Since March 2011, Syria has been going through a state of political crisis and instability resulting in an exodus of Syrians to neighboring countries. More than 1 million Syrian refugees are residents of Lebanon, Jordan, Turkey, Egypt, and North Africa (UNHCR, 2017). Most of these refugees are living in established camps that are situated in communities already occupied by nationals that are already settled and going about their day-to-day activities. The establishment of these camps resulted in competition for the limited resources such as land, water, and wood collection in the penurious semi-arid area where the refugees and host community live. According to Alexander Betts. et al (2014)Uganda hosts an estimated 1, 4 44,873 refugees with over 10 ten refugee camps spread in different parts of the country, Alexander et al,(2014) further assert that in Uganda the refugees are distributed between northern settlements camps in Yumbe (25 percent), Adjumani (20 percent), Arua (9 percent) and Moyo (7 percent), and southern and central and western sites Nakivale (12 percent), Kampala (8 percent), Rwamwanja (6 percent), Kiryandongo ( 5 percent), Kyangwali (4 percent), Kyaka II ( 2 percent), Oruchinga ( 1 percent) and Kisoro (0.02 percent). These figures do not include the self-settled "refugees" who are not under UNHCR's protection mandate. This makes Uganda Africa's largest refugee-hosting country and one of the top five worldwide. Throughout 2017, Uganda responded to three concurrent emergency influxes: South Sudan- 1,053,598, the Democratic Republic of Congo (DRC) -276,570, Burundi-40,497, Somalia-37,193, and others-37,015 (UNHCR Uganda, 2018). Despite the continuing influx of refugees the government of Uganda working with its development partners has continued to strengthen the refugee-hosting environment through the Settlement Transformative Agenda included in its five-year National Development Plan II (NDP II 2016-2020). This has offered refugees equal rights with the citizen. The continued influx of refugees and the legal frameworks that provide them with equal rights to those citizens creates conflicts and tensions amongst the host community and refugee population Crisp (2003) this friction might be brought forth by among other factors; scramble for the scarcely available resources or services or even over aid and other humanitarian aid offered by aid agencies and other donors. This kind of relationship and association composite may be influenced by a variety of factors, establishing the root causes of this friction and how to end it is the central theme for this article thus ensuring tranquility rather than conflict.

Peaceful co-existence among the refugees and local citizens of Rwamwanja Sub-county is very important for the development of refugees and citizens, (UNICEF, 2015, UNCHR 2014). However, the arrival and occupation of refugees in an area ushered in tribal conflicts as the lifestyle and livelihoods of the host community can never be the same again. The consequent influences of this can never be ignored as it was usually significant and of great magnitude, that it often defined the relationship between the local community and the refugees. The refugees were often treated with lots of care and special goods and services were allocated to them whilst neglecting the locals who face similar or even more awful situations. This has been caused by several conflicts such as political incitements, competition, deep-seated cultural values, land issues, ethnic rivalry, and idleness among the refugees. According to Gillian Nantume, (2017) refugees at the periphery of the Kyaka II refugee settlement and the host community clashed over a disputed piece of land. The refugees, 
led by their administration, carried out an eviction exercise of the nationals from the settlement land and demolished some structures, prompting the nationals to stone them. This shows the existence of conflicts between the hosts and refugee communities. Despite the many studies by the UNHCR in the last few years have focused on the causes and effects of conflict. Notably, little has been achieved on factors leading to the persistent conflicts between the citizens and the refugees in the Rwamwanja camp. The government, as well as non-government organizations such as the UN, UNHCR, WFP, LWF, and AHA, have implemented a series of conflict resolution projects among the local citizens and refugees though violent conflicts persist. Based on this background this article aimed at filling the knowledge gap by investigating how refugees' adaptability on peaceful coexistence with the local citizens in Rwamwanja sub-county in Uganda. The overall purse of this article is to establish refugees' adaptability to the peaceful coexistence with the local communities in the Rwamwanja sub-county. To achieve this goal the article is tailed on the following objectives: To assess the major causes of conflicts that are hindering the peaceful coexistence of refugees with local natives in the Rwamwanja. To find out how the influx of refugee impact the peaceful coexistence between the refugees and the hosts' communities in Rwamwanja. To examine the measures the government and development partners have instituted to mitigate the causes of conflicts that affect peaceful co-existence between refugees and host communities in Rwamwanja. The findings in this article create awareness among hosts and refugees on their need to live peacefully with support from government and development partners Like United Nations High Commissioner for Refugees. Besides, this study helped the local community to change their attitudes towards coexistence with the refugees. Jaakko Valli, co-researcher and WFP's refugee Programme manager in Uganda, said there were considerable economic benefits from the intense farming carried out by refugees on land provided by the Ugandan Government for their resettlement. This article is divided into four sections that's the introduction, background methodology literature review finding and discussion and conclusion, and recommendation.

\section{METHODOLOGY}

Mugenda (1999) described research design as an understanding of conditions for collection and analysis of data in a way that combined their relationships with the research to the economy of procedures. Mugenda (1999) suggests that research design deals with the detailing of procedures that were adopted to carry out the research study. This study employed a descriptive research design. Mugenda (1999) defines descriptive research as a process of collecting data to answer questions concerning the current status of the study subject. The designs employed both qualitative and quantitative approaches, descriptive involves a study of a particular situation and its impact to have a more accurate detail and in-depth of the nature of the phenomenon as it relates to a specific environment. It is mostly used where the purpose is to gain a rich and in-depth understanding of the context of the research and the processes being enacted (Brown, 2007). It, therefore, uses multiple data collection sources, termed triangulation. Descriptive research is a study that seeks to portray an accurate profile of persons, events or situations" (Kish, 1965). It involves formalizing the study with definite structures to better describe or present facts about a phenomenon as it is perceived or as it is in reality.

A sample population of 174 respondents determined using the Slovenes formula was drawn from a targeted population of 307 people from the Rwamwanja refugee host community. Through the purposive sampling method, the key informants were selected from the top officials at the district and through Stratified and simple random sampling other categories of respondents were also selected to participate in the study. By using questionnaires, interview guides, and documentary checklist data collection instruments that were tested for validity and reliability both primary and secondary data were collected. Ethical confirmations like consent of respondents, privacy, and confidentiality were observed during data collection. During analysis, descriptive statistics were entailed in the determination of measures of central tendency such as mean, mode, median; measures of dispersion such as range, variance, standard deviation; frequency distributions; and percentages as Adejimi, et al, (2010) advises. Inferential statistics included correlation analysis using a correlation coefficient and regression analysis using a regression coefficient to answer the research questions. Using content analysis, the researcher quantified and analyzed the presence, meanings, and relationships of such certain words, themes, or concepts. Researchers then made inferences about the messages within the texts, the writer(s), the audience, and even the culture and time surrounding the text. Qualitative data were interpreted by composing explanations or descriptions from the information. The qualitative data were illustrated and substantiated by quotation or descriptions to determine the research topic under study as Adejimi, et al, (2010) advises.

\section{LITERATURE}

\section{Drivers of Conflicts Hindering the Peaceful Coexistence of Refugees and Host Communities.}

When refugee camps were constructed also new relationships were created between refugees and the communities hosting them. What was often experienced in such scenarios was that situations of tensions and conflict between refugees and the host community prevail for different reasons. Especially camps hosting refugees from neighboring countries were prone to such political aspects, for instance, the Rwandan Tutsi refugees hosted in Uganda, which in 1990 formed 20 of the Rwandan Patriotic Army (RPA) and invaded northern Rwanda was one example (Lomo et al, 2001). Crisp (2003:9-15) described protracted situations in Africa as featured by limited physical security, violence, and frequent conflicts between refugees local populations. Crisp (2003:15) further identified two typical areas that were creating tensions in the initial 
influx stage that's the degree that locals recognized their benefits from projects and services provided to refugees and increased pressure on vital natural resources which the host community was depending upon was another possible source of conflict between them.

Jacobsen (2002:6) supported the argument by Crisp (2003) that when refugees arrived in new communities there were likely risks of security problems of different nature both between refugees and with the host community. Such conflicts varied over a broad spectrum including local crime and violence, clashes between refugees and the local community, organized crime, drug smuggling, human trafficking amongst others (Jacobsen 2002:8-9).

Why these conflicts took place was much based on contextual conditions, but some areas were recognized as more prone to conflicts to develop and escalate. Economic impacts in such an area; refugees can create problems for the host community in terms of putting more pressure on scarce economic resources. Nonetheless, the economic impacts of refugee influx were often mixed as refugees could also bring with them resources or contribute to economic stimuli to the area (Jacobsen 2002:10-11). Access to Common Property Resources (CPRs) and environmental impacts was another possible conflicting area where the worst effects occur during mass influx or mass return of refugees. As the access to natural resources are often scarce in communities where refugee camps were established more pressure could be put on these resources due to the refugee influx and act as a trigger to conflict between the two parties (Martin 2005:330-331, Jacobsen 2002:11). This indicated a difference in environmental and security impacts between self-settled refugees and refugees kept in camps where the former is more likely to adopt sustainable practices.

The Source of these conflicts cannot be evaluated in an isolated vacuum. Usually are there combinations of several impacts that create situations of conflicts between host populations and settled refugees. Social and cultural impacts can also play a role in these complex situations. For example, Jacobsen (2002:11) explains that in the border area between southern Sudan and Kenya where the majority is pursuing a pastoralist lifestyle and where cattle rustling has been a longstanding tradition. In such a scenario, refugees and hosts with cattle can face challenges in their new relationship as incidents of cattle rustling between them would be unlikely.

The inflation and availability of small arms especially in sub-Sahara Africa is also a constant threat to people's security. The Small Arms Survey (SAS) (2002:57) 2002 recognizes that around 30 million illegal small arms are in circulation in sub-Sahara Africa. The "easy" availability and access to small arms have undoubtedly been an obstacle for relief programs, peacebuilding, and development in Africa and other regions where weapons and arms are free in circulation, Mkutu (2008:1). This is also a reality faced in remote areas where refugee camps are established. As Mkutu (2008:2) describes is the flow of arms in remote, bordering, and marginalized areas proving difficult to regulate. In addition, weapons are a necessity for many ethnic groups to protect their livelihoods such as livestock from neighboring tribes due to lack of government security presence in these areas. Muggah and Muggah (2006:1) are addressing the concerns of militarization of refugee camps stating that arms availability is "especially acute in so-called protracted refugee situations". The access and availability to arms by both host communities and refugees are certainly a great security threat possibly affecting the relationship between the two.

Political actions by both hosting governments and UNHCR can also play a role in how the relationship between hosts and refugees develops. Refugees living in camps have at least to some extent access to services such as health care and education due to international aid and donor programmers, while such accesses may be limited or non-existing to the host community. Further refugees are provided with food and shelter by UNHCR (UNHCR, 2012) while host communities who are often located in remote areas struggle to meet their daily needs. Such factors can contribute to increasing tensions and instability of the relationship, which further potentially can escalate into conflicts (Loescher and Milner 2006:8-9). The experiences by the hosts are often that they are treated unfairly and that refugees living on "their land" receive services and assistance while they are neglected and marginalized. Such grievances experienced by host communities are a strong and potential source of conflict towards the refugee population (Aukot 2003:74-75). Bolesta (2005:27-28) identifies the amount of violence that takes place in refugee camps in Kenya (Dadaab and Kakuma) which she further describes as impossible to quantify. Deaths and serious injuries occur daily where safety and security fears are high within the refugee camps. These incidents include both inter-communal conflicts between refugees and also between refugees and host communities. The spillover and access to small arms in areas where refugee camps are present also play a huge part in these situations of violent encounters (Bolesta 2005:27-28). Commonly, the local people of the area have access to small arms for different reasons such as protecting cattle or history of tribal disputes.

Conflicts between refugees and people of host communities often take place within refugee camps as it often is the main area of services and resources. Refugees are also usually restricted to movement while insecurity measures inside camps are high (Crisp 2003:14-15). Nevertheless, situations of violence and conflict between refugees and hosts are also present outside the camps. In such scenarios, if donor support decreases over time refugees might be "forced" or tempted to go to search for livelihood resources in the host community which usually is illegal. Resulting in increasing competition over such resources with hosts can potentially become a source of tension, Loescher and Milner, (2006).In the worst-case 
scenario's refugees can start pursuing alternative coping strategies such as theft and banditry which obviously will have further negative effects on the relationship with the host community.

\section{Refugee's Impact on Host Communities}

The nature of the impacts of refugee influx and camp establishments on host communities are many and diverse. Exact knowledge of these impacts and how they affect host communities is nevertheless lacking according to researchers of the field such as Chambers (1986) and Maystadt and Verwimp (2009). What is known is that refugee camps are commonly established in remote areas of poor and underdeveloped conditions where often host populations are struggling to sustain their livelihoods. That implies that refugee influx will have some effect on the lives of the people living in the area. How it will impact nonetheless depends on several factors and approaches where both positive and negative outcomes are possibilities (Maystadt and Verwimp 2009:1-2).

In situations of refugee camp establishments, it is appointed usually to the United Nations High Commissioner for Refugees (UNHCR) the leading organization in addition to the hosting government and various implementing partners (UNHCR $b$. 2012). For obvious reasons is UNHCR mostly concerned with assisting refugees as their mandate responds to the same. Chambers (1986: 246) argues that research tends to emphasize more on the refugees in such situations as they are in an obvious crisis while the hosting part receives limited attention.

Literature on issues relating to the impacts of refugee camps on host communities has received equally limited attention. Maystad and Verwimp (2009:1-2) claim that knowledge and literature on these issues have not improved much since the analysis of Chambers from 1986. Responding to these claims is this research aims at contributing to the gap in knowledge of the complexity of impacts on host communities by refugee camps, and how this further affects the relationship between hosts and refugees.

People of communities hosting refugees are often experiencing similar difficult situations although they tend to be neglected in the increasing demand for attention and assistance of the refugee situation. Nevertheless, it can be argued that host communities are likely to even if in a small amount receive more attention and assistance than before the refugee presence due to the influx of relief and aid agencies to the area. The increasing demand for relief and aid assistance in areas hosting refugees will have the possibility to raise awareness of also the host communities' challenges. The effects from refugee assistance and endorsements of economic functions are likely also to some extent benefit the livelihoods of the host community. Host communities can also suffer from such developments in terms of losing out to overexploitation of limited natural resources vital for sustaining livelihoods. This emphasizes the reality of the diverse set of impacts that refugees and camp presence may have on hosting communities where mixed consequences are the most likely outcomes. In such perspectives is it argued that more research and knowledge on these issues are needed for understanding the dynamics of consequences of how refugee camps affect host communities (Maystadt and Verwimp 2009:1-2).

Chambers (1986:246-249) explains likely cost and benefits for hosts in a refugee-hosting situation into three groups of hosts; surplus farmers, subsistence farmers, and laborers with negligible or no land. Further on Chambers offers five dimensions of analysis of the cost-benefit relationship which is accordingly dependent upon food/land, labor/wages, services, common property resources (CPRs), and economic development. In the early stages of refugee influx is it likely that before imported food aid assistance is fully implemented that depletion of local food supplies will drive up food prices. The outcome for the ones selling food such as surplus farmers would likely be positive, while negative for the ones who are depending on buying food supplies such as subsistence farmers and landless laborers.

As with all possible impacts of refugee presence on the host, communities is the issue of food access and availability. For example, many presences of refugees make food scarcer for the poorer host in terms of raising prices and pressure on resources. Nevertheless, it may also have the opposite effect through relief food becoming available to hosts in terms of accessibility through trade. Although food aid distributed to refugees is obviously for personal use, it is common that portions of it are sold or exchanged for different food or other items at local markets in camps. Whitaker (1999) argues that around 75\% of food rations distributed to refugees in camps in Tanzania during the early 1990s (1992-1993) were sold at local markets. The World Food Project (WFP) and UNHCR (1998) on the other hand claim that the numbers are closer to 20 or $30 \%$. This does indicate that a significant part of food aid finds its way to markets also available for non-refugees. Such local markets and trading areas could also have social effects on the relationship between the host and refugee populations where mutual benefits could be a possible outcome (Chambers 1986:250).

Similar to the issues of land, do also labor and wages vary in their impacts on host communities. For some, it could result in cheap labor from refugees on abundant land to help produce more goods. Alternatively, if land and natural resources are scarce, hosts are likely to get hurt as competition for such resources could increase (Chambers 1986:252). The argument by Chamber on varying impacts is supported by empirical research such as by Maystadt and Verwimp (2009) from Tanzania where refugees provided cheap labor to hosts in sectors such as agriculture, construction, and others. Jacobsen (2002:10-11) supports Chambers claims that in areas where land and natural resources are scarce refugees can increase competition over these resources for host communities as experienced in refugee camps in The Horn of Africa. 
In terms of social services, it is usual that areas such as health and education receive assistance through the development of schools and health centers. In the initial face of refugee influx is it typical that these accesses are reserved for refugees, although in long term they may also bring benefits to local communities, as they will also receive more access to these services (Chambers 1986:252-253). A Development Report from 2011 (World Bank 2011:16-17) supports Chambers's arguments that social services often are improved in refugee-hosting communities, referring to experiences in Mexico in the early 1990s. Similarly, UNHCR is arguing that health and sanitation services improve in refugee-hosting communities. Data from refugee camps in Tanzania (between 1991 and 2001) suggests that around 30\% of health service beneficiaries were local people (Maystadt and Wervimp 2009:8).

Competition for common property resources (CPRs) is a typical possible conflicting issue between refugees and locals according to Chambers (1986:253-254). Cultivation of land through camp development resulting in exploitation of grazing land, trees, firewood, food, and water are some of the outcomes in the equation. In areas where these resources are limited is it likely that hosts will feel like losing out to the CPRs and possibly become a source of hostility towards the refugee population. Conflicts between hosts and refugees (also between non-refugee pastoralist communities) over CPRs have been experienced especially in the Sudan-Uganda-Kenya border region according to Jacobsen (2003:11).

Economic development within host communities as a result of refugee presence can vary a great deal. As expressed by Alix-Garcia and Saah (2009: 167) through a World Bank economic review discussing the economic impacts of refugee camps on host communities which can both be positive and negative. Newmarket opportunities for locals to sell local merchandise may have a positive effect for some, while at the same time competition over already scarce resources may bring challenges for others. Experiences from refugee camps in Tanzania between 1993 and 1994 shows that hosts with farming opportunities experienced positive economic impacts through increased food demand (excluding food-aid) from refugees. On the other hand, non-farming hosts suffered from increasing food prices (Alix-Garcia and Saah 2009:166).

Cheap labor, trading, framing, etc. can stimulate the economic development of the hosting area. Infrastructural improvements such as new roads, access to markets and goods can also raise economic activity. Population growth through non-refugee migration to the area due to opportunities accompanied by the refugee presence may also impact in different ways. The nature of the economic development will nevertheless depend on official policies and interventions of the hosting country (Chambers 1986: 255-256). This shows some of the complexity of possible impacts refugee influx may have on the economic as well as overall situation for people of host communities. Whitaker's (2002) work on the impact of refugees in host communities also gives a brighter attraction in this regard. He states that social relations between refugees and hosts also had negative consequences. He indicates that refugee camps or settlements are associated with problems such as drunkenness, prostitution, and social promiscuity. And that crime rate rises sharply in refugee situations, especially for murder, armed robbery, and illegal possession of firearms.

On this basis, Whitaker (2002:345) opined that the sudden presence of refugees and relief resources changed social and economic opportunities for host communities in both negative and positive ways. For instance, the local hosts who already had access to resources, education, or power positively benefit from the refugee presence as some local hosts take advantage of changing opportunities for their benefit, especially with the increased local upsurge in business and trade. Whitaker concludes that the changing dynamics associated with refugee presence in the community also create different impacts on the host based on the socio-economic conditions, the nature of host-refugee relations, and gender among other factors.

Sanjugta (2003) explored the socio-cultural impact of refugees on developing or host communities. This study encompasses the issues of social or relational as well as the religious, linguistic, and ethnic character which arise when large groups of refugees arrive within a given host community. She explored this type of impact concerning communities within the nations of Pakistan and Tanzania - two of the main refugee-hosting nations in the world. Pakistan currently provides asylum for around 2 million Afghans, a number that has continued to rise and fall since 1979 when the Soviets invaded that country during the Cold War. The host government sometimes responds negatively toward the refugees, suggesting it holds a fear that the refugees might pose a threat to national security. Refugees' impacts on host countries are controversial and little understood.

\section{Measures for Mitigate the Causes of Conflict between Refugees and Host Communities}

The good practice and programs of interventions by governments and partners designed to prevent or address the conflict between refugees and host communities and recommendations on refugee-host conflict. It also presents good practice lessons from the programs.

The literature report highlights three main types of programs that have been designed to tackle tensions and conflicts between refugees and host communities. In several cases these programs overlap:

Integrated development programs- integrated humanitarian and development programs that seek to balance assistance to both refugee and host communities, or integrate services provided to them as shown from countries like Guinea, Kenya, Sudan, Uganda, Afghanistan, Pakistan, Nepal, Lebanon, and Ecuador. 
Conflict resolution programs- programs that encourage workshops, discussions, or regular meetings between both communities. These may involve training in conflict resolution skills or peace education.

Environmental management programs- programs that seek to improve the management of environmental/natural resources to promote cooperation and reduce tensions.

\section{Integrated and Balanced Assistance}

Many agencies stress the importance of providing both humanitarian and long-term development assistance to both refugee and host communities and present this as a key mechanism for reducing tensions and conflicts between the two groups, (Jacobsen 2002, Ikanda,2008, RSC 2010). Health and education are often identified as key areas for joint refugee/ host provision (OECD 2001). Even in cases where conflict prevention is not a stated or the primary goal, integrated development programs can help to reduce tensions. Berry (2008) stresses the importance of development projects for refugee-hosting areas as a whole, not simply in terms of their immediate benefits such as improved healthcare, but because of the impact they can have on reducing tensions between host and refugee populations.

Konyndyk (2005) highlights the need to balance levels of services available to both populations while engaging the host population in the provision of services to refugees. He argues that this can decrease tensions between the two groups while creating a concrete incentive for the host population to be more welcoming to the refugees. One form that this can take is the provision of health services through existing local health structures, Konyndyk (2005).

Konyndyk (2005) also suggests that assistance levels to refugee populations should be reduced as vulnerability decreases. At the same time, agencies should support activities that promote refugee self-sufficiency. He suggests that this may involve introducing a cost-share approach to some service provision, which could be shared by the host and refugee communities. The goal of promoting integrated approaches has often been undermined by humanitarian agencies' efforts to promote selfreliance. Dryden-Petersen and Hovil (2003) argue that interventions to boost refugees' self-sufficiency must be accompanied by interventions designed to socially and economically integrate the refugee population.

The view that donor assistance to refugee populations should also involve a focus on improving refugee-hosting areas has long been recognized by the major agencies working in this area. The concept of targeted development assistance (TDA) refers to aid that 'focuses on the needs of both refugees and host communities through, for example, improving livelihood opportunities, service provision or infrastructure. It aims to enhance refugees' access to rights, self-sufficiency, and, where possible, local integration', Betts $(2009,1)$. This approach does not necessarily seek to prevent conflicts or tensions but may help to achieve these aims. Betts $(2009,2)$ outlines the key determinants of successful TDA: 'Institutional collaboration between UNHCR and development actors; Joined-up government and new budget lines that can transcend government department divides; and, most crucially; the right kinds of interventions, which are based on an integrated approach, focus on livelihoods, use pre-existing community structures, and use evaluations to monitor and follow-up on project implementations'.

Betts $(2009,2-3)$ states that the following interventions are necessary to achieve an effective integrated development approach towards refugees: A systematic analysis of the lessons from the past practice of applying development assistance to enhance refugee protection. Independent consultations with donor and host state to better understand states' concerns and interests to identify the basis of mutually beneficial 'win-win' cooperation. At the national level, more coherent coordination between ministries of development, home affairs, and foreign affairs, including the creation of new interministerial budget lines for "development assistance and refugees". Development actors such as UNDP and the World Bank should recognize the important potential role played by refugees in national development, and the possible 'binding constraint' they pose on development when neglected. UNHCR should play a catalytic role in facilitating inter-state and inter-agency dialogue on development assistance and refugees as an important component of its ongoing work on protracted refugee situations. An example of this approach is UNHCR's (2002) 'Agenda for Protection. The agenda encourages states to consider allocating development funds to programs simultaneously benefiting refugees and host populations. It also encourages host populations to consider including refugee-hosting areas in their national development plans to achieve the broad goal of sharing burdens and responsibilities more equitably and building capacities to receive and protect refugees.

\section{Advocacy and Host Government Policy}

How protracted refugee crises are handled by host governments and aid agencies drives conflict with local populations because it discourages local integration and encourages corruption, Aukot (2003). The refugee policies of the host government are a key determinant of refugees' vulnerability and their ability to pursue livelihoods. In many host countries, refugees are treated as illegal migrants, with few rights and little protection, Jacobsen (2002).

Most studies stress that host governments should be clear on their stance towards local integration, meet their responsibilities to improve socio-economic conditions in areas affected by protracted refugee situations, and support the 
full integration of refugees instead of confining them to camps Ikanda(2008), Agblorti(2011). Refugees' lack of freedom of movement hinders self-sufficiency and creates economic and social seclusion, Jacobsen (2002).

Konyndyk (2005) suggests that donors and humanitarian agencies should increase efforts to persuade governments and host populations to allow refugees fuller access to economic opportunities. Jacobsen (2002) argues that donors should encourage host governments and local authorities to see the value to their people in supporting and allowing livelihood activities for displaced people. Advocacy might focus on the following key areas: reducing restrictions on the movement of refugees, ensuring existing property rights are available to refugees; and helping negotiate access to land and common resources for refugees, Berry (2008). In a case study from Ghana, Agblorti (2011) highlights the relationship between the host population and the camp administration as an important factor in determining refugee-host relations. In this case, the host community consistently blamed their difficulties on the administration and believed that the administration was unfairly diverting resources (including resettlement packages) from the host community. He argues that the camp administration's relationship with the host population needs to be evaluated and taken into consideration and that regular meetings should take place between the administration and the host community, Agblorti(2011).

\section{FINDING AND DISCUSSION}

From the findings it can be observed that the majority of the respondents were females with 208(52.2\%) respondents, their counterparts the males were 190(47.8\%). This implied that the majority of the refugees in the camp were females meaning that women are more affected by civil wars in the world since they are the indigent, marginalized and vulnerable persons in society.

\section{Drivers of Conflicts hindering the peaceful coexistence of refugees and host communities.}

The under-given inferences that were made regarding the major causes of conflicts that were hindering the peaceful coexistence of refugees with local natives, based on the analysis. Results showed that many activities lead to conflict in camps. As a result, political issues, security tensions from the neighboring countries where the refugees come from caused conflicts between the refugees and the local natives. This was supported by Crisp (2003:9-15) who described protracted situations in Africa as featured by limited physical security, violence, and frequent conflicts between refugee's local populations. Root causes for such uprising conflicts between refugees and the local population were complex and many. Crisp (2003:15) identified two typical areas that were creating tensions in the initial influx stage. The first one depended on the degree that locals recognized their benefits from projects and services provided to refugees. Increased pressure on vital natural resources which the host community was depending upon was another possible source of conflict between them. Causes of conflicts between refugees and hosts were not a straightforward process to identify, as many variables and impacts were affecting the relationship. Jacobsen (2002:6) also supports the arguments by Crisp (2003) that when refugees arrived in new communities there were likely risks of security problems of different nature both between refugees and with the host community. Such conflicts varied over a broad spectrum including local crime and violence, clashes between refugees and the local community, organized crime, drug smuggling, human trafficking amongst others (Jacobsen 2002:89). Why these conflicts took place was much based on contextual conditions, but some areas were recognized as more prone to conflicts to develop and escalate. Economic impacts in such areas; refugees could create problems for the host community in terms of putting more pressure on scarce economic resources. Nonetheless, the economic impacts of refugee influx were often mixed as refugees can also bring with them resources or contribute to economic stimuli to the area (Jacobsen 2002:10-11). Access to Common Property Resources (CPRs) and environmental impacts was another possible conflicting area where the worst effects occurred during mass influx or mass return of refugees. As the access to natural resources were often scarce in communities where refugee camps were established more pressure could be put on these resources due to the refugee influx and acted as a trigger to conflict between the two parties

Results from interviews indicated that there was a correlation between causes of conflicts and the peaceful coexistence of refugees in the Rwamwanja refugee settlement in western Uganda

The settlement commandant of Rwamwanja stated:

"Since people living in the camp are from different walks of life, it becomes difficult for them to stay at peace with each other....most of them are competing for resources which are not sometimes enough for everyone. Natives look at refugees as intruders and the reverse may be true".

This meant that causes of conflicts contribute negatively to the peaceful coexistence of refugees in the Rwamwanja refugee settlement. This further implied that the more the conflicts, the more the confusion in the settlement and thus leading to poor development. This disagreed with the hypothesis that there is no significant relationship between causes of conflicts and the peaceful coexistence of refugees with the natives.

\section{Refugee's impact on host communities}


Findings on the impacts of refugee's settlement on host communities 30\% respondents strongly agreed, $20 \%$ agreed, and $10 \%$ disagreed and $3 \%$ strongly disagreed that refugees have an impact on host communities. And the data from interviews indicated that 'people of communities hosting refugees were often experiencing difficult situations although they were neglected in the increasing demand for attention and assistance of the refugee situation. Nevertheless, it was argued that host communities were likely to even if in a small amount receive more attention and assistance than before the refugee presence due to the influx of relief and aid agencies to the area. The increasing demand for relief and aid assistance in areas hosting refugees could raise awareness of the host communities' challenges. The effects from refugee assistance and endorsements of economic functions were likely to some extent benefit the livelihoods of the host community. Host communities suffered from such developments in terms of losing out to overexploitation of limited natural resources vital for sustaining livelihoods.

The peaceful coexistence of refugees with local natives was significantly decreasing. This is in line with the evidence from the literature showed that a competition for common property resources (CPRs) which was a typical conflicting issue between refugees and locals according to Chambers (1986:253-254). Cultivation of land through camp development resulted in the exploitation of grazing land, trees, firewood, food, and water. In areas where these resources were limited, the hosts felt like losing out to the CPRs and become a source of hostility towards the refugee population. Furthermore, conflicts between hosts and refugees (between non-refugee pastoralist communities) over CPRs were experienced especially in the Sudan-Uganda-Kenya border region according to Jacobsen (2003:11). This proved the non-peaceful coexistence of the refugees and local natives (host communities) due to the gaps prevailing in the host communities. Another evidence in literature is that of Whitaker (2002:345) who opine that the sudden presence of refugees and relief resources changed social and economic opportunities for host communities in both negative and positive ways. For instance, the local hosts who already had access to resources, education, or power positively benefited from the refugee presence as some local hosts took advantage of changing opportunities for their benefit, especially with an increased local upsurge in business and trade.

\section{Measures for mitigating the causes of conflict between refugees and host communities}

The under-given inferences that were made regarding measures to put in place to curb down the challenges, based on the analysis several measures have been put in place to curb the challenges; The government selected Kyenjonjo and Kyegegwa districts, this was evident by $77 \%$ of the respondents who strongly agreed, $20 \%$ agreed that there were measures to overcome conflicts and $3 \%$ were not sure of what is supposed to be done, $0 \%$ disagreed and $0 \%$ strongly disagreed. This was in line with the need to understand the social security needs of different categories of poor people in Uganda, the sources and types of risks confronting the host communities, and the different arrangements and strategies (informal, market-based, and public) for risk reduction, mitigation and coping used by development partners and the government. To have a real picture of the refugee adaptability and peaceful coexistence with local native's western Uganda, we must understand the extent of redistribution across generation's for example in Uganda, UNHCR worked with the government to improve living conditions for Sudanese refugees living in the West Nile districts and 1998 launched an integrated approach, the Self-Reliance Strategy (SRS). Its overarching goal was 'to integrate the services provided to the refugees into regular government structures and policies and, in so doing, to move 'from relief to development.

\section{CONCLUSION AND RECOMMENDATION}

There is a significant correlation between the causes of conflicts and the peaceful coexistence of refugees with the natives. A refugee settlement that is not well managed disrupts the development process of the camp and the whole region at large because different natives and some refugees may keep some grudges at heart which may not foster development in the area.

According to the study findings, there were many development partners often identified as Non-Governmental Organizations. Such organizations played a catalytic role in facilitating inter-state and inter-agency dialogue on development assistance and refugees as an important component of its ongoing work on protracted refugee situations. An example of that approach was UNHCR's (2002) 'Agenda for Protection. The agenda encouraged states to consider allocating development funds to programs simultaneously benefiting refugees and host populations. It also encouraged host populations to consider including refugee-hosting areas in their national development plans to achieve the broad goal of sharing burdens and responsibilities more equitably and building capacities to receive and protect refugees. Although Non-Governmental Organizations have become progressively more involved in development assistance, at every level. The shift from a relief and welfare focus had not been seen in an attempt to address the underlying causes of some of those fabricated disasters/conflicts

For refugee adaptability and peaceful coexistence to be realized, the government and development partners must be available and established under national law; which should include being financially viable, sustainable, and responsive to conditions; the government needed to be clear on its stance towards local integration and not give off mixed messages in that regard. In particular, clear guidelines for implementing local integration, including readily available information for 
refugees. To understand the refugee adaptability and peaceful coexistence with local natives it is recommended that Donors and humanitarian agencies work with local organizations that are familiar with the political and security context, and can provide guidance about how to distribute resources or implement programs. The host governments should be clear towards local integration, meet their responsibilities to improve socio-economic conditions in areas affected by protracted refugee situations and support the full integration of refugees instead of confining them to camps. Government should recruit welltrained managers and administrators who have relevant skills and knowledge to steer up the settlement for development and peaceful coexistence for all stakeholders. In instances where deficiencies are identified, government and top management should organize seminars and workshops to bridge the foregoing gaps in the refugee settlement. Finally, management of the settlement should keep on organizing periodical meetings with the stakeholders so that problems or challenges can be identified and solutions sought jointly for amicable settlement and development.

\section{REFERENCES}

Ali, J. A., \&Ocha, W. (2018). East Africa Refugee Crisis: Causes of Tensions and Conflicts between the Local Community and Refugees in Kakuma Refugee Camp, Kenya. Journal of Social Science Studies, 5(1), 298. https://doi.org/10.5296/jsss.v5i1.12512

Baez, J. E. (2011). Civil wars beyond their borders: The human capital and health consequences of hosting refugees. Journal of Development Economics, 96(2), 391-408. https://doi.org/10.1016/j.jdeveco.2010.08.011

Barnett-Page, E.; Thomas, J. Methods for the synthesis of qualitative research: A critical review. BMC Bed.Res. Methodol. 2009, 9, 59. [CrossRef] [PubMed]

Bram J. Jansen, Journal of Refugee Studies, Volume 29, Issue 2, 1 June 2016, Pages 149 165,https://doi.org/10.1093/jrs/fev018

Cornelius, W. A. \& Rosenblum, M. R. (2003). Center for Comparative Immigration Studies UC Journal, (working paper Centre for comparative immigration studies), http://escholarship.org/uc/item/9vt1199x

1977-1999.

San Diego. Wall Street Retrieved from

Denyer, D.; Tranfield, D. Producing a Systematic Review; Sage Publications Ltd.: Thousand

Oaks, CA, USA, 2009.

Duff, A. The literature search: A library-based model for information skills instruction. Libr. [CrossRef]

Rev. 1996,45, 14-18.

El-Khatib, Z., Scales, D., Vearey, J., \& Forsberg, B. C. (2013). Syrian refugees, between the rocky crisis in Syria and hard inaccessibility to healthcare services in Lebanon and Jordan. Conflict and Health, 7(1). https://doi.org/10.1186/17521505-7-18

Gina Porter Kate Hampshire Peter Kyei Michael Adjaloo George Rapoo Kate Kilpatrick Journal of Refugee Studies, Volume 21, Issue 2, 1 June 2008, Pages 230 252,https://doi.org/10.1093/jrs/fen015

Harden, A.; Garcia, J.; Oliver, S.; Rees, R.; Shepherd, J.; Brunton, G.; Oakley, A. Applying systematic review methods to studies of people's views: An example from public health research. J. Epidemiol. Community Health2004, 58, 794-800. [CrossRef] [PubMed]

Higgins, J.P.; Green, S. Cochrane Handbook for Systematic Reviews of Interventions; Wiley Online ～Library: Hoboken, NJ, USA, 2008; Volume 5.

Jadad, A.R.; Cook, D.J.; Jones, A.; Klassen, T.P.; Tugwell, P.; Moher, M.; Moher, D. Methodology and reports of systematic reviews and meta-analyses: A comparison of Cochrane reviews with articles published in paper-based journals. JAMA 1998, 280, 278 280. [CrossRef] [PubMed]

Leenders, R. (2008). Iraqi Refugees in Syria: Causing a spillover of the Iraqi conflict? Third 29(8), 1563-1584. https://doi.org/10.1080/01436590802528721

Nyaoro, D. (2010). Policing with prejudice: How policing exacerbates poverty among urban Journal of Human Rights, 14(1), 126-145. https://doi.org/10.1080/13642980902933753

Pittaway, L.; Robertson, M.; Munir, K.; Denyer, D.; Neely, A. Networking and innovation: A the evidence. Int. J. Manag. Rev. 2004, 5, 137-168. [CrossRef]

Rashman, L.; Withers, E.; Hartley, J. Organizational learning and knowledge in public service systematic review of the literature. Int. J. Manag. Rev. 2009, 11, 463
494. [CrossRef]
World Quarterly,

refugees. International systematic review of organizations: A 
Staples, M.; Niazi, M. Experiences using systematic review guidelines. J. Syst. Softw. 2007, 80, $1425-$ 1437.[CrossRef]

Taylor, J. Edward (2016). "Research: Refugees Can Bolster a Region's Economy." Harvard October 5; https://hbr.org/2016/10/research-refugees-can-bolster regions economy.

Business Review,

Taylor, J. Edward and Mateusz Filipski (2014). Beyond Experiments in Development Economics: Local Economywide Impact Evaluation. Oxford: Oxford University Press.

Taylor, J. Edward, Mateusz Filipski, Mohamad Alloush, Anubhab Gupta, Irvin Rojas, and Ernesto Gonzalez (2016). "Economic Impact of Refugees." PNAS_Proceedings of the National Academy of Sciences, vol. 113 no. 27

Tranfield, D.; Denyer, D.; Smart, P. Towards a methodology for developing evidence-informed management knowledge using systematic review. Br. J. Manag. 2003, 14, 207-222. [CrossRef]

Tranfield, D.; Denyer, D.; Smart, P. Towards a methodology for developing evidence-informed management knowledge using systematic review. Br. J. Manag. 2003, 14, 207-222. [CrossRef]

Walton, O. (2012), Good practice in preventing conflict between refugees and host communities (GSDRC Helpdesk Research Report), Birmingham, UK: Governance and Social Development Resource Centre, University of Birmingham. 